\title{
Psychometric properties of the quality of life scale Child Health and Illness Profile-Child Edition in a combined analysis of five atomoxetine trials
}

\author{
Alexander Schacht $\cdot$ Rodrigo Escobar • \\ Thomas Wagner $\cdot$ Peter M. Wehmeier
}

Received: 20 June 2011 / Accepted: 19 September 2011/Published online: 11 October 2011

(C) The Author(s) 2011. This article is published with open access at Springerlink.com

\begin{abstract}
Our aim was to evaluate the psychometric properties of the generic quality of life $(\mathrm{QoL})$ scale Child Health and Illness Profile-Child Edition (CHIP-CE) by means of a combined analysis of atomoxetine clinical trials in children and adolescents with attention-deficit/hyperactivity disorder (ADHD). Individual patient-level data from five clinical trials were included in the combined analysis. Psychometric properties of the CHIP-CE were explored in terms of internal consistency and structure. Patients $(n=794)$ aged between 6 and 15 years (mean 9.7) with mean baseline ADHD Rating Scale of $41.8 \pm 8.04$ were included. On average, 0.7 (SD 2.23)
\end{abstract}

Trial registration: This is a combined analysis of five already published clinical trials.

Preliminary results of this analysis have been presented at the EPA meeting 2009.

The following publication is based on the same data base but focuses on the clinical-relevant treatment differences and does not contain the psychometrical evaluation of the scale: see citation, Escobar et al. (2010).

\section{A. Schacht ( $\square)$}

Lilly Deutschland, Global Statistical Sciences,

Werner-Reimers-Str. 2-4, 61350 Bad Homburg, Germany

e-mail: schacht_alexander@lilly.com

\section{R. Escobar}

Neuroscience Products, Medical Science,

Lilly Research Laboratories, Sannomiya Plaza Bldg. 7-1-5,

Isogamidori, Chuo-ku, Kobe 651-0086, Japan

e-mail: escobar_rodrigo@lilly.com

T. Wagner

Trilogy Writing \& Consulting GmbH,

Falkensteiner Str. 77, 60322 Frankfurt, Germany items were missing for the whole CHIP-CE. The internal consistency of the CHIP-CE assessed by Cronbach's alpha was good for all sub-domains at baseline and at endpoint. Considerable ceiling effects were only observed for the "restricted activity" sub-domain. No considerable floor effects were seen. The factor analysis supported the 12 -factor solution for the sub-domains, but not the 5-factor solution for the domains. Our analyses were based on a large sample of non-US patients which allowed the measurement of clear changes in QoL over time. The results support that the CHIP-CE scale is psychometrically robust over time in terms of internal consistency and structure.

Keywords Attention-deficit disorder with hyperactivity · Quality of life · Psychometrics · Factor analysis

\section{Introduction}

Attention-deficit/hyperactivity disorder (ADHD) is a disorder characterized by hyperactivity, impulsivity, and inattention that affects between 3 and $7 \%$ of school-age

\footnotetext{
P. M. Wehmeier

Vitos Hospital for Psychiatry and Psychotherapy,

Weilstr. 10, 35789 Weilmünster, Germany

P. M. Wehmeier

Department of Child and Adolescent Psychiatry, Central Institute of Mental Health, University of Heidelberg, J5, 68159 Mannheim, Germany
} 
children (APA 2000). A worldwide pooled prevalence of $5.29 \%$ has been reported (Polanczyk et al. 2007). Impairment of ADHD affects cognitive and psychosocial functioning (Barkley 2002; Biederman and Faraone 2005; Nijmeijer et al. 2008; Escobar et al. 2008) as well as the quality of life (QoL) in patients and their families (Johnston and Mash 2001; Sawyer et al. 2002; Klassen et al. 2004; Matza et al. 2004; Escobar et al. 2005; Riley et al. 2006b).

Treatment options for ADHD include psychostimulants, especially in combination with behavioral therapy (MTA study) (Jensen et al. 2001) or atomoxetine, which is a nonstimulant treatment option for ADHD (Cheng et al. 2007). In most of the studies evaluating the efficacy of these medications, questionnaires such as the ADHD Rating Scale (ADHD-RS) (DuPaul et al. 1998a; Faries et al. 2001) or the clinical global impression (CGI) (Guy 1976; NIMH 1985) have been used as outcome measures for the core symptoms of ADHD.

Health-related QoL has received increasing attention both from clinicians and from investigators in children and adolescents with ADHD (Harpin 2005; Hakkart-van Roijen et al. 2007; Yang et al. 2007; Bastiaens 2008). Healthrelated QoL is a multidimensional concept that reflects the subjective physical, social, and psychological aspects of health and is distinct from symptoms of the disorder and objective functional outcomes (Wallander et al. 2001). It strongly depends on the subjectively perceived impact of the disorder (and of the respective treatment) on the level of physical, psychological, and social functioning (Leidy et al. 1999; Revicki et al. 2000). Some psychometric instruments are available to assess the health-related QoL, including the Child Health and Illness Profile, Child Edition (CHIP-CE) (Riley et al. 2001; Riley et al. 2006b) and the Child Health Questionnaire (CHQ) (Landgraf et al. 1996). These questionnaires are generic scales that assess QoL aspects that go beyond the core symptoms of the disorder and reflect various dimensions of QoL. CHIP-CE has child-, adolescent- and parent-rated versions, allowing the assessment of the patient's QoL both from the parent's and from the patient's perspective. The possibility to assess QoL from different perspectives is a promising characteristic of this instrument for assessing QoL in children and adolescents (Schmidt et al. 2001).

A number of studies have shown improvement in healthrelated QoL in children and adolescents treated with atomoxetine (Michelson et al. 2001; Buitelaar et al. 2004; Perwien et al. 2004; Matza et al. 2006; Brown et al. 2006; Perwien et al. 2006; Prasad et al. 2007; Wehmeier et al. 2007, 2008). These studies have used the CHQ, the CHIP$\mathrm{CE}$, or other QoL instruments.

Up to now, the psychometric properties of the CHIP-CE were mostly studied in non-ADHD populations using cross-sectional data only. Only Riley et al. (2006b) discuss some psychometric properties of this generic scale in an ADHD population. They found that internal consistency reliability was good-to-excellent (Cronbach's $\alpha>0.70$ ) for all CHIP-CE domains and sub-domains and that almost no ceiling and floor effects were observed. A factor analysis of the sub-domains yielded a 12-factor solution. The domainlevel factor analysis identified six factors, the four domains of Satisfaction, Comfort, Resilience and Risk avoidance and in addition the two sub-domains of the Achievement domain. Moderate to high correlations between the CHIP$\mathrm{CE}$ scales and measures of ADHD and family factors were found. The HRQoL of children in this sample was considerably lower than that of community youth. However, this analysis has some limitations. First, the patients were not required to have been diagnosed formally with ADHD but only the clinical judgment of the investigator if the patient has hyperactive/inattentive/impulsive symptoms/ problems and had not been formally diagnosed with ADHD or a hyperactive/inattentive/impulsive syndrome in the past was required for inclusion into the study. Another analysis of the study data showed that $11.5 \%$ of patients did not fulfill strict ADHD criteria (Döpfner et al. 2006). In addition, only cross-sectional data were analyzed making any statements about score sensitivity for changes over time impossible.

The objectives of the present combined analysis were to evaluate the psychometric properties of the CHIP-CE at baseline and over time and to assess the correlation between parameters related to $\mathrm{QoL}$ and those related to ADHD core symptoms using the individual patient data of five clinical trials studying atomoxetine in children and adolescents with ADHD.

\section{Methods}

Study design and procedures

Individual patient-level data from five clinical trials (four European and one Canadian, all of which were studies of atomoxetine using the CHIP-CE) with similar inclusion and exclusion criteria and similar duration (8-12 weeks' follow-up) were included in the combined analysis. More details about the trials are reported elsewhere (Escobar et al. 2010). Thus, all data from clinical trials studying atomoxetine and using the CHIP-CE in the Lilly data base were included. The total number of patients included in the combined analysis was 794. Three of these studies were randomized, double-blind trials comparing atomoxetine with placebo: Study $1(n=99)$ (Svanborg et al. 2009), Study $2(n=149)$ (Escobar et al. 2007; Montoya et al. 2007), and Study 3 ( $n=139)$ (Curatolo et al. 2007). The 
fourth study was a randomized, open-label study of atomoxetine versus standard of care (Study 4, $n=201$ ) (Prasad et al. 2007), and the last one was an open-label atomoxetine study (Study 5, $n=206$ ) (Dickson et al. 2007), where all patients received atomoxetine.

All patients met the DSM-IV diagnostic criteria for ADHD and had a symptom severity of at least 1.5 standard deviations (SD) above norm values for the ADHDRS (ADHD subscale of the SNAP in Study 3). The diagnosis was confirmed using the Kiddie-Schedule for Affective Disorders and Schizophrenia for School-Aged Children-Present and Lifetime Version (K-SADS-PL) in all studies except in Study 5. In Studies 2 and 3, basal CGI-S scores for ADHD were at least 4 or higher. The double-blind treatment period was between 8 and 12 weeks in the placebo-controlled studies ( 8 weeks for Study 3, 10 weeks for Study 1, and 12 weeks for Study 2). Studies 2 and 4 included only medication-naïve patients. Study 3, which was carried out in Italy, did not explicitly require medication-naivve patients, but at the time of recruitment, there were no ADHD drugs available in that country.

The primary scale on which this combined analysis was based is the Child Health and Illness Profile-Child EditionParent Form (CHIP-CE-Parent Form) (Riley et al. 2001), a 76-item generic health-related quality of life (HR-QoL) questionnaire, covering a total of five domains (Satisfaction, Comfort, Risk avoidance, Resilience, and Achievement) and twelve sub-domains (satisfaction with health (SH), satisfaction with self (SS), physical comfort (PC), emotional comfort (EC), restricted activity (RA), individual risk avoidance (IRA), threats to achievement (TA), family involvement (FI), physical activity (PA), social problem solving (SPS), academic performance (AP), and peer relations (PR)) that were developed in non-ADHD samples. The CHIP-CE scores are standardized to $t$-scores, i.e., to a mean $( \pm \mathrm{SD})$ of $50( \pm 10)$, based on the norm values, which were derived from a sample of 1,049 school children from the United States, with higher scores indicating better health. Riley et al. (2004a) found that its domains (Satisfaction, Comfort, Risk Avoidance, Resilience, and Achievement) measure structurally distinct, interrelated aspects of health. Furthermore, they summarized that the domain reliability was high with an internal consistency between 0.79 and 0.88 and a retest reliability between 0.71 and 0.85 as measured by the intra-class correlation ICC.

Efficacy on core ADHD symptoms was assessed using the Attention Deficit/Hyperactivity Disorder Rating ScaleIV, Parent Version (ADHD-RS), which evaluates all 18 symptoms of ADHD according to the DSM-IV diagnostic criteria (Guy 1976; DuPaul et al. 1998b). Improvement is indicated by a decrease in the score. The ADHD-RS comprises a total score, a hyperactive/impulsive sub-score, and an inattentive sub-score.

Statistical analysis

The demographic data were analyzed using descriptive statistics. The number of missing items per evaluation was computed and also analyzed descriptively as a continuous variable. The proportion of evaluations without missing items was presented for the CHIP-CE as a whole and for the domains and sub-domains. All visits and all five studies were pooled for this analysis. Inclusion of patients receiving active treatment and placebo in the analysis over time will increase the range of the changes and will thus lead to a wider basis for the evaluation. The item-total correlations (Spearman's and Pearson's correlation coefficients) were calculated for the total scores as well as for the domains and sub-domains. Furthermore, the sub-domains were correlated with the domains and the total score, and the domains were correlated with the total score. The items/sub-domains/domains were sorted by their Spearman's correlation coefficient with the respective summary score. Only the Spearman's correlation coefficient is reported here because it is similar to the Pearson's correlation coefficient for these data. Cronbach's alpha was computed for the items that were grouped into a sub-score and for all subsets of items that can be created by deleting one item within a sub-domain. The relative frequencies of floor effects (lowest possible value observed) and ceiling effects (highest possible value observed) for the subdomains, domains, and total scores are provided. Correlations between domains of the CHIP-CE at baseline and at endpoint are shown. The same was done for the subdomains. A factor analysis based on the sub-domains was performed additionally in order to explore the relationships between the sub-domains. Factor analyses using the varimax rotation on the 76 items with solutions allowing 5 or 12 factors were performed because the CHIP-CE has 5 domains and 12 sub-domains, as the goal was to replicate the factor structure seen in the normative sample. Only loadings $>0.30$ are presented. All analyses were done using the SAS statistical program.

\section{Results}

Patient population and disposition

A total of 794 patients were included in the analysis. The age range was $6-15$ years. The mean age was 9.7 years (SD 2.30 years). Most of the patients were children ( $<12$ years): $611(77.0 \%)$ and male $658(82.9 \%)$. Mean ADHD-RS total score at baseline was 41.8 (SD 8.04), the 
Table 1 Descriptive analysis (mean and SD) of CHIP-CE total score, domains, and sub-domains at baseline based on all five studies

\begin{tabular}{lll}
\hline Score & Non-missing observations & Mean \pm SD \\
\hline Total score & 793 & $28.9 \pm 11.76$ \\
Satisfaction & 788 & $34.4 \pm 14.04$ \\
Satisfaction with health & 787 & $40.8 \pm 13.5$ \\
Satisfaction with self & 788 & $31.5 \pm 14.37$ \\
Comfort & 792 & $43.7 \pm 10.82$ \\
Physical comfort & 792 & $51.0 \pm 9.92$ \\
Emotional comfort & 791 & $38.2 \pm 11.78$ \\
Restricted activity & 760 & $49.7 \pm 10.25$ \\
Risk avoidance & 791 & $30.2 \pm 14.62$ \\
Ind. risk avoidance & 792 & $35.7 \pm 15.6$ \\
Threats to achievement & 790 & $30.9 \pm 13.6$ \\
Resilience & 792 & $36.0 \pm 12.03$ \\
Family involvement & 791 & $40.2 \pm 11.68$ \\
Physical activity & 791 & $46.4 \pm 11.77$ \\
Social problem solving & 789 & $35.3 \pm 12.97$ \\
Achievement & 777 & $30.5 \pm 10.4$ \\
Academic performance & 776 & $31.0 \pm 9.95$ \\
Peer relations & 790 & $37.1 \pm 13.42$ \\
\hline
\end{tabular}

inattentive sub-score was 22.2 (SD 3.83), and the hyperactive/impulsive sub-score was 19.6 (SD 6.03). At baseline, mean CGI-S ADHD was 4.8 points (SD 0.89). Baseline total CHIP-CE mean $t$ score was $28.9( \pm 11.76)$ (standard: $50 \pm 10$ ); for details, see Table 1. A more detailed discussion of the impact of ADHD on QoL as measured by the CHIP-CE can be found elsewhere (Escobar et al. 2005, 2010).

Internal psychometric properties of the CHIP-CE

\section{Missing values}

The proportion of CHIP-CE evaluations with at least one missing value was $19.4 \%$. On average, 0.7 (SD 2.23) items were missing for the whole scale. The proportion of CHIP$\mathrm{CE}$ evaluations with at least one missing value in one of the domains ranged between $4.1 \%$ (Resilience domain) and 9.5\% (Comfort domain). The sub-domain with the lowest proportion of missing values was the PA sub-domain $(0.7 \%)$, whereas the sub-domain TA had the highest number of missing values $(6.2 \%)$. On average, 0.2 (or less) items (SDs 0.19-0.96) were missing for the various domains and sub-domains.

\section{Item-total correlations}

To give a clearer impression of item to total score correlation, not all 76 correlations between the individual items and the total score are shown here. Instead, the quartiles of the 76 Spearman's correlation coefficients are reported. At baseline, the highest correlation with the total score was $r=0.581 ; 25 \%$ of the items had a higher correlation than $r=0.455$. The median correlation was $r=0.374 ; 75 \%$ of the items had a higher correlation than $r=0.245$. The lowest correlation was $r=0.055$. Item 45 ("How often did your child play hard enough to start sweating and breathing hard?") had the lowest correlation ( $r=0.055$; 95\% CI 0.016 to 0.127$)$ and was the only item where zero was included in the $95 \%$ CI (i.e., where the correlation was not significantly higher than 0 ). A similar pattern of correlations was found at the end of the double-blind phase for the placebo-controlled studies. Overall, smaller correlations were observed when correlating the changes from baseline. The highest correlation was $r=0.502$, the $25 \%$ quartile was $r=0.337$, the median was $r=0.274$, the $75 \%$ quartile was $r=0.211$, and the lowest correlation was $r=0.063$.

\section{Item-domain correlations}

Within the various CHIP-CE domains, the highest and the lowest Spearman's correlations between the individual items and the respective domain are reported in the following. The highest baseline correlation in the Satisfaction domain was $r=0.743$ and the smallest was $r=0.512$. Correlations in the Comfort domain were between $r=0.305$ and $r=0.602$, for the Resilience domain between $r=0.265$ and $r=0.643$, and for the Achievement domain between $r=0.468$ and $r=0.624$. For the Risk avoidance domain, correlations ranged from $r=0.268$ (item 76 "How often did he/she have trouble paying attention in school?") to a maximum of $r=0.747$. However, the second lowest correlation within the Risk avoidance domain had a correlation of $r=0.501$. Such a large difference between item and domain correlation was not seen for the other domains, where the single itemdomain correlations were more evenly distributed between the minimum and maximum values.

Correlations were similar at the end of the double-blind phase for the placebo-controlled studies. However, the correlation for item 76 ("How often did he/she have trouble paying attention in school?") was not as distinct from other item to domain correlations as for the baseline assessment in the Risk avoidance domain.

Overall, lower correlations were seen for changes from baseline. Here, correlations were between $r=0.386$ and $r=0.664$ for the Satisfaction domain, between $r=0.184$ and $r=0.526$ for the Comfort domain, between $r=0.215$ and $r=0.527$ for the Risk avoidance domain, between $r=0.139$ and $r=0.524$ for the Resilience domain, and 
between $r=0.329$ and $r=0.694$ for the Achievement domain.

\section{Item-sub-domain correlations}

Within the CHIP-CE sub-domains, the highest and lowest Spearman's correlations between the individual items and the respective sub-domain were also analyzed. At baseline (endpoint values are provided in brackets), the highest correlation for the SH sub-domain was $r=0.682(0.759)$ and the smallest was $r=0.590(0.601)$. For the SS subdomain, the correlations were between $r=0.703(0.709)$ and $r=0.876(0.868)$, for the PC sub-domain between $r=0.437(0.314)$ and $r=0.620(0.666)$, for the EC subdomain between $r=0.527$ (0.528) and $r=0.684$ ( $r=0.758)$, for the RA sub-domain between $r=0.556$ (0.608) and $r=0.863$ (0.869), for the IRA sub-domain between $r=0.670$ (0.626) and $r=0.889$ (0.853), for the FI sub-domain between $r=0.419$ (0.432) and $r=0.656$ (0.690), for the SPS sub-domain between $r=0.721$ (0.655) and $r=0.825$ (0.807), for the AP sub-domain between $r=0.641$ (0.615) and $r=0.784$ (0.818), and for the PR sub-domain between $r=0.618$ (0.573) and $r=0.832$ (0.858). For the TA sub-domain, the minimal and maximal correlations were $r=0.286$ (item 76) (0.361) and $r=0.712$ (0.678), respectively. However, the item with the second lowest correlations within this sub-domain had a correlation of $r=0.563(0.490)$, showing that item
76 had a particularly low correlation within this subdomain. The items for the PA sub-domain were separated into two groups based on the correlations. Items $44-46 \mathrm{had}$ correlations between $r=0.778$ (0.730) and $r=0.830$ (0.832), whereas the items 31-33 had correlations between $r=0.323$ (0. 345) and $r=0.408$ (0.377). A similar pattern, but with generally smaller correlations, was observed for the changes from baseline.

Table 2 shows the Spearman's correlation coefficients between the sub-domains and the domains and between the domains and the total score.

\section{Internal consistency (Cronbach's alpha)}

Internal consistency of CHIP-CE was assessed using Cronbach's alpha. The results are shown in Table 3. The internal consistency was good for all sub-domains at baseline and at endpoint. Only the EC and FI sub-domains fell short of a consistency of 0.7 , which can be used as a helpful cut-off (DeVellis 1991). However, no such cut-off was previously discussed for changes over time. The internal consistency for changes from baseline to endpoint was fair, except for AP, which had better internal consistency for changes over time. The internal consistency of all sub-domains at baseline and endpoint was robust against single missing items, as the alpha values did not decrease by any meaningful degree when one item was deleted. The TA domain and the AP sub-domains were sensitive to

Table 2 Spearman's correlation coefficients with 95\% CIs between the sub-domains and the domains and between the domains and the total score at baseline, at endpoint after the placebo-controlled period, and for the change from baseline to that endpoint

\begin{tabular}{llll}
\hline Sub-domains & At baseline & At endpoint & For change from baseline to endpoint \\
\hline Satisfaction with health & $0.879(0.860 ; 0.897)$ & $0.888(0.865 ; 0.912)$ & $0.817(0.771 ; 0.862)$ \\
Satisfaction with self & $0.855(0.833 ; 0.876)$ & $0.868(0.839 ; 0.897)$ & $0.853(0.819 ; 0.888)$ \\
Emotional comfort & $0.866(0.848 ; 0.884)$ & $0.872(0.846 ; 0.898)$ & $0.813(0.770 ; 0.855)$ \\
Physical comfort & $0.745(0.709 ; 0.780)$ & $0.739(0.689 ; 0.788)$ & $0.680(0.616 ; 0.744)$ \\
Restricted activity & $0.575(0.525 ; 0.625)$ & $0.509(0.429 ; 0.589)$ & $0.491(0.404 ; 0.578)$ \\
Threats to achievement & $0.944(0.936 ; 0.953)$ & $0.930(0.912 ; 0.948)$ & $0.910(0.885 ; 0.935)$ \\
Ind. risk avoidance & $0.823(0.798 ; 0.849)$ & $0.756(0.708 ; 0.804)$ & $0.657(0.587 ; 0.726)$ \\
Social problem solving & $0.737(0.703 ; 0.772)$ & $0.750(0.702 ; 0.797)$ & $0.702(0.642 ; 0.762)$ \\
Family involvement & $0.705(0.667 ; 0.742)$ & $0.724(0.669 ; 0.778)$ & $0.633(0.561 ; 0.705)$ \\
Physical activity & $0.526(0.472 ; 0.580)$ & $0.541(0.463 ; 0.618)$ & $0.520(0.439 ; 0.601)$ \\
Peer relations & $0.754(0.721 ; 0.787)$ & $0.777(0.732 ; 0.821)$ & $0.701(0.644 ; 0.758)$ \\
Academic performance & $0.727(0.691 ; 0.764)$ & $0.760(0.712 ; 0.809)$ & $0.830(0.782 ; 0.877)$ \\
Domain & & & $0.687(0.625 ; 0.749)$ \\
Achievement & $0.734(0.698 ; 0.770)$ & $0.786(0.739 ; 0.832)$ & $0.651(0.582 ; 0.719)$ \\
Satisfaction & $0.723(0.686 ; 0.760)$ & $0.785(0.745 ; 0.825)$ & $0.662(0.595 ; 0.729)$ \\
Risk avoidance & $0.703(0.664 ; 0.742)$ & $0.653(0.593 ; 0.713)$ & $0.589(0.518 ; 0.660)$ \\
Resilience & $0.625(0.579 ; 0.671)$ & $0.667(0.606 ; 0.728)$ & $0.599(0.530 ; 0.668)$ \\
Comfort & $0.589(0.539 ; 0.638)$ & $0.513(0.432 ; 0.594)$ & \\
\hline
\end{tabular}


Table 3 Cronbach's alpha (standardized) for the subdomains and the lowest alpha that was reached by deleting an item in that sub-domain with $95 \%$ CIs

\begin{tabular}{|c|c|c|c|}
\hline Sub-domains & At baseline & At endpoint & $\begin{array}{l}\text { For change from } \\
\text { baseline to endpoint }\end{array}$ \\
\hline \multicolumn{4}{|c|}{ Cronbach's alpha (standardized) with $95 \%$ CIs } \\
\hline Satisfaction with health & $0.771(0.747 ; 0.796)$ & $0.801(0.770 ; 0.832)$ & $0.611(0.550 ; 0.672)$ \\
\hline Satisfaction with self & $0.815(0.793 ; 0.836)$ & $0.831(0.803 ; 0.859)$ & $0.676(0.622 ; 0.730)$ \\
\hline Physical comfort & $0.726(0.697 ; 0.755)$ & $0.689(0.642 ; 0.736)$ & $0.567(0.501 ; 0.633)$ \\
\hline Emotional comfort & $0.822(0.803 ; 0.841)$ & $0.835(0.810 ; 0.861)$ & $0.760(0.723 ; 0.797)$ \\
\hline Restricted activity & $0.799(0.776 ; 0.823)$ & $0.865(0.842 ; 0.888)$ & $0.746(0.703 ; 0.789)$ \\
\hline Ind. risk avoidance & $0.816(0.795 ; 0.838)$ & $0.740(0.697 ; 0.784)$ & $0.597(0.530 ; 0.665)$ \\
\hline Threats to achievement & $0.821(0.802 ; 0.840)$ & $0.789(0.756 ; 0.821)$ & $0.679(0.628 ; 0.729)$ \\
\hline Family involvement & $0.705(0.674 ; 0.736)$ & $0.713(0.669 ; 0.757)$ & $0.560(0.492 ; 0.627)$ \\
\hline Physical activity & $0.729(0.698 ; 0.760)$ & $0.699(0.649 ; 0.750)$ & $0.589(0.521 ; 0.656)$ \\
\hline Social problem solving & $0.828(0.809 ; 0.847)$ & $0.803(0.771 ; 0.835)$ & $0.663(0.609 ; 0.718)$ \\
\hline Academic performance & $0.775(0.747 ; 0.803)$ & $0.831(0.796 ; 0.867)$ & $0.738(0.682 ; 0.794)$ \\
\hline Peer relations & $0.822(0.803 ; 0.842)$ & $0.804(0.772 ; 0.836)$ & $0.450(0.362 ; 0.539)$ \\
\hline \multicolumn{4}{|c|}{ Lowest Cronbach's alpha (standardized) with $95 \%$ CIs by deleting an item in the respective domain } \\
\hline Satisfaction with health & $0.724(0.694 ; 0.755)$ & $0.760(0.722 ; 0.798)$ & $0.544(0.472 ; 0.617)$ \\
\hline Satisfaction with self & $0.712(0.677 ; 0.747)$ & $0.754(0.710 ; 0.797)$ & $0.553(0.474 ; 0.632)$ \\
\hline Physical comfort & $0.688(0.655 ; 0.721)$ & $0.627(0.570 ; 0.684)$ & $0.500(0.423 ; 0.576)$ \\
\hline Emotional comfort & $0.793(0.771 ; 0.815)$ & $0.808(0.778 ; 0.837)$ & $0.723(0.680 ; 0.766)$ \\
\hline Restricted activity & $0.705(0.669 ; 0.742)$ & $0.784(0.745 ; 0.823)$ & $0.612(0.543 ; 0.681)$ \\
\hline Ind. risk avoidance & $0.692(0.654 ; 0.729)$ & $0.568(0.492 ; 0.645)$ & $0.388(0.280 ; 0.496)$ \\
\hline Threats to achievement & $0.792(0.770 ; 0.814)$ & $0.757(0.720 ; 0.795)$ & $0.639(0.582 ; 0.696)$ \\
\hline Family involvement & $0.642(0.604 ; 0.681)$ & $0.653(0.599 ; 0.707)$ & $0.481(0.400 ; 0.562)$ \\
\hline Physical activity & $0.675(0.637 ; 0.713)$ & $0.639(0.579 ; 0.700)$ & $0.505(0.423 ; 0.587)$ \\
\hline Social problem solving & $0.771(0.745 ; 0.797)$ & $0.742(0.699 ; 0.786)$ & $0.566(0.493 ; 0.639)$ \\
\hline Academic performance & $0.685(0.645 ; 0.726)$ & $0.764(0.712 ; 0.816)$ & $0.639(0.560 ; 0.718)$ \\
\hline Peer relations & $0.764(0.736 ; 0.791)$ & $0.719(0.672 ; 0.766)$ & $0.327(0.215 ; 0.439)$ \\
\hline
\end{tabular}

certain items in terms of change. Alpha was below 0.4 for these sub-domains based on the changes from baseline to endpoint when one item was deleted.

\section{Floor and ceiling effects}

Floor and ceiling effects were evaluated using the baseline visits and all subsequent visits to increase the basis of information, as these effects should not occur at any time. The floor and ceiling effects of the total score were less than $0.1 \%$ at baseline and across all visits. The same holds for the floor effects of all domains. The largest ceiling effect of the domains was seen for the Satisfaction domain when all visits were pooled (1.3\%). Floor effects of the sub-domains were mostly below $1 \%$. The AP sub-domain had the largest floor effect based on baseline values $(3.5 \%)$. Ceiling effects varied across the different sub-domains and were generally lower if only the baseline visit was taken into account. At baseline, the ceiling effect was below $1 \%$ for the sub-domains SH, TA, AP, and PR. The ceiling effect increased to values between 1 and $2 \%$ if all visits were taken into account. The sub-domains SS (baseline),
EC (baseline and for all visits), IRA (baseline), FI (baseline and for all visits), and SPS (baseline and for all visits) had values between 1 and 5\%. Higher ceiling effects were discovered for the sub-domains SS (all visits: 6.9\%), PC (baseline: $5.9 \%$, all visits: $9.1 \%$ ), RA (baseline: $54.6 \%$, all visits: $58.7 \%$ ), IRA (all visits: $8.2 \%$ ), and PA (baseline: $7.3 \%$, all visits: $8.9 \%$ ).

\section{Factor analyses based on individual items}

Factor analyses with solutions allowing 5 or 12 factors were performed because the CHIP-CE has 5 domains and 12 subdomains (see Tables 4, 5 for the loadings). The factor analysis was based on baseline data only. The first factor of the 12-factor solution mainly consists of items from the subdomains IRA and TA, which together form the Risk avoidance domain. High loadings of the second factor came almost exclusively from the EC domain. The third factor had high loadings not only from all four SS items, but also from two items from the SH sub-domain (item 1: "How often does your child have a lot of fun?" and item 4: "How often does your child feel happy?"). The 5 items of the SPS sub-domain 
composed the fourth factor. These items did not load onto other factors and no other item loaded to any relevant degree onto factor four. The 3 out of 6 PA items, which were related to running and walking, loaded high onto the fifth factor, together with smaller loading from item 34 ("Feel too sick to play at home?"), item 10 ("My child is physically fit"), and item 11 ("My child is well coordinated"). All AP items loaded high onto the sixth factor, together with smaller loadings from two TA items (item 74: "How often did he/she get along with his/her teacher?" and item 76: "How often did he/she have trouble paying attention in school?"). The AP items loaded nearly exclusively onto this factor. Only the five PR items loaded onto factor seven, and only two of these items had smaller loadings onto the first factor. No loadings onto any relevant degree for the PR items were observed in terms of any other factor. The four items composing the RA sub-domain made up almost exclusively the factor eight. Again, only one of these items had a smaller loading onto another factor. Factor nine contained all nine PC items, which loaded only onto this factor (except for item 5). All FI items made up factor ten. Loadings of these items onto other factors were minor. The group of PA items that relate to games and sports loaded high onto factor eleven. Factor twelve received loadings from four of the six items of the $\mathrm{SH}$ sub-domain, three of which did not load onto other factors. Also, an EC item (item 21: "How often did your child have trouble falling asleep?") and a PC item (item 5: "How often is your child sick?") loaded onto this factor.

The result of a factor analysis based on 5 factors is shown in Table 4. All but one item of the Risk avoidance items (item 76) loaded onto the first factor displayed in the first column. Additionally, two items from the Comfort domain, four items from the Achievement domain, and four items from the Resilience domain loaded onto this factor. These loadings were generally smaller than the loadings from the Risk avoidance items. All of the Comfort domain items, which are related to RA, loaded onto the second factor as displayed in the second column. Furthermore, seven of the nine Comfort domain items, which belong to the PC sub-domain, had loading onto the second factor. The other two PC items did not have loadings of more than 0.3 onto any factor. Only one of the other comfort items (i.e., those related to EC) had a small loading for this factor. Those three of six PA items from the Resilience domain that were related to running and walking loaded high onto this factor too. Furthermore, three SH items had medium loadings onto this factor. All the SS items loaded onto the third factor together with four $\mathrm{SH}$ items. This factor also received high loadings from the four Achievement domain items of which the PR sub-domain consists. Smaller loadings were also seen for Resilience items, which were mostly related to PA (i.e., games and sports). The fourth factor consisted mainly of items related to EC and received almost no loadings from the other two Comfort sub-domains. Smaller loadings also came from a few Satisfaction items. The fifth and last factor received loadings mainly from the FI sub-domain, which belongs to the Resilience domain, and the AP sub-domain, which belongs to the Achievement domain.

\section{Correlations between domains of the CHIP-CE}

Table 6 shows the correlations between the domains at baseline and at endpoint. Most correlations were higher at endpoint than at baseline. The pattern of correlations was similar in both analyses. The Risk avoidance domain had the lowest correlations compared with other domains, both at baseline and at endpoint. However, this was not the case for changes from baseline to endpoint. The highest correlation for change was seen between the Achievement and Risk avoidance domains ( $r=0.462$ ), followed by the domains Comfort versus Satisfaction $(r=0.360)$, Resilience versus Satisfaction $(r=0.323)$, Risk avoidance versus Comfort $(r=0.309)$, Achievement versus Satisfaction $(r=0.290)$, Achievement versus Resilience $(r=0.270)$, Resilience versus Risk avoidance $(r=0.261)$, Achievement versus Comfort $(r=0.221)$, Resilience versus Comfort $(r=0.212)$, and Risk avoidance versus Satisfaction $(r=0.198)$.

\section{Correlations between sub-domains of the CHIP-CE}

Table 7 shows the correlations between the sub-domains at baseline and at endpoint. Six sub-domains (SH, SS, EC, TA, SPS, and PR) correlate with three or more other sub-domains with $r>0.3$, both at baseline and at endpoint. Three further sub-domains correlate with three or more other sub-domains with $r>0.3$, at baseline (PC, RA, and IRA). The highest correlations found were $r=0.603$ at baseline and $r=0.559$ at endpoint. Three sub-domains appear to be correlated with other sub-domains to a lower degree. At baseline, all correlations were less than 0.3 for FI. At endpoint, only the correlations with SS $(r=0.412)$ and with SPS $(r=0.319)$ were higher than 0.3 . PA is correlated $(r>0.3)$ with SH only at baseline $(r=0.368)$ and at endpoint $(r=0.393)$. AP is not correlated with any other sub-domain at baseline and only with TA at endpoint $(r=0.356)$. For correlations between changes from baseline to endpoint, only four correlations were stronger than 0.3: SS versus $\mathrm{SH}(r=0.441)$, AP versus TA $(r=0.380)$, TA versus IRA $(r=0.336)$, and PC versus $\mathrm{SH}(r=0.307)$.

\section{Factor analyses based on original sub-domains of CHIP-CE}

A factor analysis based on the sub-domains is another approach to exploring relationships between sub-domains 
Table 4 Factor analysis with 12 factors (varimax rotation) for the CHIP-CE (only loadings $>0.30$ are presented)

\begin{tabular}{|c|c|c|c|c|c|c|c|c|c|c|c|c|c|}
\hline Items & Sub-domains & 1 & 2 & 3 & 4 & 5 & 6 & 7 & 8 & 9 & 10 & 11 & 12 \\
\hline 1 & SH & & & 0.61 & & & & & & & & & \\
\hline 2 & SH & & & & & & & & & & & & 0.64 \\
\hline 3 & SH & & & & & & & & & & & & 0.60 \\
\hline 4 & $\mathrm{SH}$ & & 0.31 & 0.61 & & & & & & & & & \\
\hline 5 & $\mathrm{PC}$ & & & & & & & & 0.32 & 0.39 & & & 0.41 \\
\hline 6 & SS & & & 0.71 & & & & & & & & & \\
\hline 7 & SS & & & 0.78 & & & & & & & & & \\
\hline 8 & SS & & & 0.70 & & & & & & & & & \\
\hline 9 & SS & & & 0.58 & & & & & & & & & \\
\hline 10 & SH & & & & & 0.48 & & & & & & 0.32 & \\
\hline 11 & SH & & & & & 0.33 & & & & & & & 0.32 \\
\hline 12 & $\mathrm{SH}$ & & & & & & & & & & & & 0.36 \\
\hline 13 & $\mathrm{PC}$ & & & & & & & & & 0.34 & & & \\
\hline 14 & $\mathrm{PC}$ & & & & & & & & & 0.50 & & & \\
\hline 15 & $\mathrm{PC}$ & & & & & & & & & 0.55 & & & \\
\hline 16 & $\mathrm{PC}$ & & & & & & & & & 0.68 & & & \\
\hline 17 & $\mathrm{PC}$ & & & & & & & & & 0.41 & & & \\
\hline 18 & $\mathrm{PC}$ & & & & & & & & & 0.51 & & & \\
\hline 19 & $\mathrm{PC}$ & & & & & & & & & 0.53 & & & \\
\hline 20 & $\mathrm{PC}$ & & & & & & & & & 0.49 & & & \\
\hline 21 & $\mathrm{EC}$ & & 0.37 & & & & & & & & & & 0.35 \\
\hline 22 & $\mathrm{EC}$ & & 0.62 & & & & & & & & & & \\
\hline 23 & $\mathrm{EC}$ & 0.33 & 0.49 & & & & & & & & & & \\
\hline 24 & $\mathrm{EC}$ & & 0.55 & & & & & & & & & & \\
\hline 25 & $\mathrm{EC}$ & & 0.66 & & & & & & & & & & \\
\hline 26 & $\mathrm{EC}$ & 0.33 & 0.65 & & & & & & & & & & \\
\hline 27 & $\mathrm{EC}$ & & 0.68 & & & & & & & & & & \\
\hline 28 & $\mathrm{EC}$ & & 0.72 & & & & & & & & & & \\
\hline 29 & $\mathrm{EC}$ & & 0.63 & & & & & & & & & & \\
\hline 30 & RA & & & & & & & & 0.59 & & & & \\
\hline 31 & PA & & & & & 0.77 & & & & & & & \\
\hline 32 & PA & & & & & 0.81 & & & & & & & \\
\hline 33 & $\mathrm{PA}$ & & & & & 0.72 & & & & & & & \\
\hline 34 & RA & & & & & 0.40 & & & 0.62 & & & & \\
\hline 35 & RA & & & & & & & & 0.67 & & & & \\
\hline 36 & RA & & & & & & & & 0.70 & & & & \\
\hline 37 & FI & & & 0.31 & & & & & & & 0.39 & & \\
\hline 38 & FI & & & & & & & & & & 0.31 & & \\
\hline 39 & FI & & & & & & & & & & 0.46 & & \\
\hline 40 & FI & & & & & & & & & & 0.7 & & \\
\hline 41 & FI & & & 0.34 & & & & & & & 0.39 & & \\
\hline 42 & FI & & & & & & & & & & 0.67 & & \\
\hline 43 & FI & & & & & & & & & & 0.65 & & \\
\hline 44 & PA & & & & & & & & & & & 0.73 & \\
\hline 45 & PA & & & & & & & & & & & 0.76 & \\
\hline 46 & PA & & & & & & & & & & & 0.80 & \\
\hline 47 & FI & & & & & & & & & & 0.60 & & \\
\hline 48 & IRA & 0.55 & & & & & & & & & & & \\
\hline
\end{tabular}


Table 4 continued

\begin{tabular}{|c|c|c|c|c|c|c|c|c|c|c|c|c|c|}
\hline Items & Sub-domains & 1 & 2 & 3 & 4 & 5 & 6 & 7 & 8 & 9 & 10 & 11 & 12 \\
\hline 49 & IRA & 0.77 & & & & & & & & & & & \\
\hline 50 & IRA & 0.75 & & & & & & & & & & & \\
\hline 51 & IRA & 0.56 & & & & & & & & & & & \\
\hline 52 & PR & & & & & & & 0.66 & & & & & \\
\hline 53 & PR & & & & & & & 0.75 & & & & & \\
\hline 54 & PR & 0.35 & & & & & & 0.65 & & & & & \\
\hline 55 & PR & & & & & & & 0.68 & & & & & \\
\hline 56 & TA & 0.68 & & & & & & & & & & & \\
\hline 57 & TA & 0.58 & & & & & & & & & & & \\
\hline 58 & TA & 0.68 & & & & & & & & & & & \\
\hline 59 & TA & 0.69 & & & & & & & & & & & \\
\hline 60 & PR & 0.35 & & & & & & 0.53 & & & & & \\
\hline 61 & TA & 0.54 & & & & & & & & & & & \\
\hline 62 & TA & 0.49 & & & & & & & & & & & \\
\hline 63 & TA & 0.54 & & & & & & & & & & & \\
\hline 64 & SPS & & & & 0.70 & & & & & & & & \\
\hline 65 & SPS & & & & 0.71 & & & & & & & & \\
\hline 66 & SPS & & & & 0.7 & & & & & & & & \\
\hline 67 & SPS & & & & 0.66 & & & & & & & & \\
\hline 68 & SPS & & & & 0.75 & & & & & & & & \\
\hline 69 & $\mathrm{AP}$ & & & & & & 0.82 & & & & & & \\
\hline 70 & $\mathrm{AP}$ & & & & & & 0.72 & & & & & & \\
\hline 71 & $\mathrm{AP}$ & & & & & & 0.66 & & & & & & \\
\hline 72 & $\mathrm{AP}$ & & & & & & 0.72 & & & & & & \\
\hline 73 & TA & 0.54 & & & & & & & & & & & \\
\hline 74 & TA & 0.38 & & & & & 0.32 & & & & & & \\
\hline 75 & $\mathrm{AP}$ & 0.36 & & & & & 0.44 & & & & & & \\
\hline 76 & TA & & & & & & 0.49 & & & & & & \\
\hline
\end{tabular}

$S H$ satisfaction with health, $S S$ satisfaction with self, $P C$ physical comfort, $E C$ emotional comfort, $R A$ restricted activity, $I R A$ individual risk avoidance, $T A$ threats to achievement, $F I$ family involvement, $P A$ physical activity, $S P S$ social problem solving, $A P$ academic performance, $P R$ peer relations

(see Table 8). This approach takes all correlations into account simultaneously. The pattern of correlations described above is confirmed with this method. The subdomains IRA, TA, SPS, and PR load strongly onto the first factor. The second factor consists mainly of the three Comfort sub-domains. Each of the other three factors (3, 4, and 5) received high loading from one of the individual sub-domains mentioned above. The second highest loading for the third factor after PA is SH. The second highest loading for the fourth factor after FI is SS. TA and AP load onto factor 5 .

\section{Correlations between CHIP-CE and ADHD-RS}

At baseline, correlations between the total score, the domains, and the sub-domains of the CHIP-CE versus ADHD-RS total score were low $(<0.4)$ (e.g., CHIP-CE total score: $r=-0.345)$ except for the Risk avoidance domain $(r=-0.517)$ and its sub-domains (individual risk avoidance $r=-0.481$, threats to achievement $r=$ $-0.463)$. More detailed information about these correlations between CHIP-CE and ADHD-RS as well as the treatment effect of atomoxetine in terms of these scales can be found elsewhere (Escobar et al. 2010). A more detailed profile over time of the CHIP-CE was evaluated in the SUNBEAM study by Prasad et al. (2007).

\section{Discussion}

The objective of this combined analysis was to evaluate the psychometric properties of the CHIP-CE in a sample of children and adolescents with ADHD from clinical studies. The analyses were based on the data from five clinical trials 
Table 5 Factor analysis with five factors (varimax rotation) for the CHIP-CE (only loadings $>0.30$ are presented)

\begin{tabular}{|c|c|c|c|c|c|c|c|}
\hline Items & Sub-domains & Domains & 1 & 2 & 3 & 4 & 5 \\
\hline 1 & SH & Satisfaction & & & 0.54 & 0.31 & \\
\hline 2 & SH & Satisfaction & & 0.41 & & 0.31 & \\
\hline 3 & SH & Satisfaction & & & & & \\
\hline 4 & SH & Satisfaction & & & 0.52 & 0.44 & \\
\hline 5 & $\mathrm{PC}$ & Comfort & & 0.59 & & & \\
\hline 6 & SS & Satisfaction & & & 0.50 & 0.33 & 0.34 \\
\hline 7 & SS & Satisfaction & & & 0.51 & 0.40 & \\
\hline 8 & SS & Satisfaction & & & 0.50 & & \\
\hline 9 & SS & Satisfaction & & & 0.48 & & 0.37 \\
\hline 10 & SH & Satisfaction & & 0.46 & 0.41 & & \\
\hline 11 & SH & Satisfaction & & & 0.32 & & \\
\hline 12 & SH & Satisfaction & & 0.55 & & & \\
\hline 13 & PC & Comfort & & & & & \\
\hline 14 & $\mathrm{PC}$ & Comfort & & 0.42 & & & \\
\hline 15 & $\mathrm{PC}$ & Comfort & & & & & \\
\hline 16 & PC & Comfort & & 0.44 & & & \\
\hline 17 & $\mathrm{PC}$ & Comfort & & 0.40 & & & \\
\hline 18 & $\mathrm{PC}$ & Comfort & & 0.42 & & & \\
\hline 19 & $\mathrm{PC}$ & Comfort & & 0.40 & & & \\
\hline 20 & $\mathrm{PC}$ & Comfort & & 0.40 & & 0.32 & \\
\hline 21 & EC & Comfort & & & & 0.45 & \\
\hline 22 & EC & Comfort & & & & 0.69 & \\
\hline 23 & EC & Comfort & 0.31 & & & 0.52 & \\
\hline 24 & EC & Comfort & & & & 0.52 & \\
\hline 25 & EC & Comfort & & & & 0.59 & \\
\hline 26 & EC & Comfort & 0.31 & & & 0.63 & \\
\hline 27 & EC & Comfort & & & & 0.60 & \\
\hline 28 & EC & Comfort & & & & 0.65 & \\
\hline 29 & EC & Comfort & & 0.34 & & 0.51 & \\
\hline 30 & RA & Comfort & & 0.51 & & & \\
\hline 31 & PA & Resilience & & 0.55 & & & \\
\hline 32 & PA & Resilience & & 0.58 & & & \\
\hline 33 & PA & Resilience & & 0.60 & & & \\
\hline 34 & RA & Comfort & & 0.64 & & & \\
\hline 35 & RA & Comfort & & 0.67 & & & \\
\hline 36 & RA & Comfort & & 0.68 & & & \\
\hline 37 & FI & Resilience & & & & & 0.46 \\
\hline 38 & FI & Resilience & & & & & 0.41 \\
\hline 39 & FI & Resilience & & & & & \\
\hline 40 & FI & Resilience & & & & & 0.50 \\
\hline 41 & FI & Resilience & & & 0.32 & & 0.40 \\
\hline 42 & FI & Resilience & & & & & 0.50 \\
\hline 43 & FI & Resilience & & & & & 0.50 \\
\hline 44 & PA & Resilience & & & 0.47 & & \\
\hline 45 & PA & Resilience & & & 0.37 & & \\
\hline 46 & PA & Resilience & & & 0.42 & & \\
\hline 47 & FI & Resilience & & & & & 0.33 \\
\hline 48 & IRA & Risk avoidance & 0.52 & & & & \\
\hline
\end{tabular}


Table 5 continued

\begin{tabular}{|c|c|c|c|c|c|c|c|}
\hline Items & Sub-domains & Domains & 1 & 2 & 3 & 4 & 5 \\
\hline 49 & IRA & Risk avoidance & 0.75 & & & & \\
\hline 50 & IRA & Risk avoidance & 0.72 & & & & \\
\hline 51 & IRA & Risk avoidance & 0.55 & & & & \\
\hline 52 & PR & Achievement & & & 0.53 & & \\
\hline 53 & PR & Achievement & & & 0.64 & & \\
\hline 54 & PR & Achievement & 0.47 & & 0.49 & & \\
\hline 55 & PR & Achievement & 0.35 & & 0.52 & & \\
\hline 56 & TA & Risk avoidance & 0.70 & & & & \\
\hline 57 & TA & Risk avoidance & 0.54 & & & & \\
\hline 58 & TA & Risk avoidance & 0.66 & & & & \\
\hline 59 & TA & Risk avoidance & 0.65 & & & & \\
\hline 60 & PR & Achievement & 0.43 & & & & \\
\hline 61 & TA & Risk avoidance & 0.50 & & & & \\
\hline 62 & TA & Risk avoidance & 0.51 & & & & \\
\hline 63 & TA & Risk avoidance & 0.57 & & & & \\
\hline 64 & SPS & Resilience & 0.34 & & 0.42 & & \\
\hline 65 & SPS & Resilience & 0.46 & & 0.39 & & \\
\hline 66 & SPS & Resilience & & & 0.50 & & \\
\hline 67 & SPS & Resilience & 0.31 & & 0.38 & & 0.34 \\
\hline 68 & SPS & Resilience & 0.45 & & 0.46 & & \\
\hline 69 & AP & Achievement & & & & & 0.58 \\
\hline 70 & $\mathrm{AP}$ & Achievement & & & & & 0.52 \\
\hline 71 & $\mathrm{AP}$ & Achievement & & & & & 0.48 \\
\hline 72 & $\mathrm{AP}$ & Achievement & & & & & 0.44 \\
\hline 73 & TA & Risk avoidance & 0.62 & & & & \\
\hline 74 & TA & Risk avoidance & 0.45 & & & & 0.32 \\
\hline 75 & $\mathrm{AP}$ & Achievement & 0.40 & & & & 0.33 \\
\hline 76 & TA & Risk avoidance & & & & & \\
\hline
\end{tabular}

Table 6 Spearman's correlation coefficients between domains of the CHIP-CE at baseline (above diagonal) and at endpoint (below diagonal)

\begin{tabular}{llllll}
\hline & Satisfaction & Comfort & Risk avoidance & Resilience & Achievement \\
\hline Satisfaction & 1 & 0.420 & 0.226 & 0.448 & 0.426 \\
Comfort & 0.366 & 1 & 0.326 & 0.195 & 0.258 \\
Risk avoidance & 0.245 & 0.281 & 1 & 0.305 & 0.452 \\
Resilience & 0.528 & 0.168 & 0.285 & 1 & 0.322 \\
Achievement & 0.523 & 0.175 & 0.500 & 0.444 & 1 \\
\hline
\end{tabular}

of atomoxetine. The descriptive CHIP-CE baseline data of these studies confirmed the impairment in terms of QoL in this clinical trial population with moderate core symptoms severity. The psychometric evaluation of the CHIP-CE showed a low number of missing items, confirming that the questionnaire comprising 76 items is relatively easy to apply (Riley et al. 2004a, 2006b). The correlations between the items and the total score were stable over time as the item-total correlations showed a similar pattern at baseline and after the double-blind phase for the placebo-controlled studies. Smaller correlations were observed between changes from baseline values. The similarity of the correlations at baseline and at endpoint indicates that the total score was sensitive to the same items at both points in time, a result that could not be shown by the cross-sectional analysis by Riley et al. (2004a, 2006b). The same holds true for the various domains. Interestingly, the item-total correlations varied widely for the Risk avoidance domain. Such a gap was not seen for any of the other domains. The item with the weakest correlation to the domain score 
Table 7 Spearman's correlation coefficients $(>0.3)$ between sub-domains of the CHIP-CE at baseline (above diagonal) and at endpoint (below diagonal)

\begin{tabular}{|c|c|c|c|c|c|c|c|c|c|c|c|c|}
\hline & SH & SS & PC & EC & RA & IRA & TA & FI & PA & SPS & AP & PR \\
\hline SH & 1 & 0.520 & 0.358 & 0.338 & 0.319 & & & & 0.368 & & & 0.394 \\
\hline SS & 0.559 & 1 & & 0.325 & & & & & & 0.329 & & 0.379 \\
\hline PC & & & 1 & 0.389 & 0.405 & & & & & & & \\
\hline EC & & 0.319 & 0.406 & 1 & 0.325 & 0.345 & 0.380 & & & & & \\
\hline RA & 0.363 & & 0.402 & & 1 & & & & & & & \\
\hline IRA & & & & & & 1 & 0.603 & & & 0.343 & & 0.312 \\
\hline TA & & & & 0.365 & & 0.483 & 1 & & & 0.421 & & 0.362 \\
\hline FI & & 0.412 & & & & & & 1 & & & & \\
\hline PA & 0.393 & & & & & & & & 1 & & & \\
\hline SPS & 0.307 & 0.367 & & & & & & 0.319 & & 1 & & 0.372 \\
\hline AP & & & & & & & 0.356 & & & & 1 & \\
\hline PR & 0.482 & 0.421 & & & & 0.326 & 0.346 & & & 0.399 & & 1 \\
\hline
\end{tabular}

Table 8 Factor analysis loadings ( $>0.3$ ) based on sub-domains of the CHIP-CE at baseline (varimax rotation)

\begin{tabular}{|c|c|c|c|c|c|}
\hline Sub-domain & Factor 1 & Factor 2 & Factor 3 & Factor 4 & Factor 5 \\
\hline Satisfaction with health & & 0.42 & 0.56 & 0.38 & \\
\hline Satisfaction with self & 0.40 & & & 0.62 & \\
\hline Physical comfort & & 0.81 & & & \\
\hline Emotional comfort & 0.34 & 0.74 & & & \\
\hline Restricted activity & & 0.59 & 0.48 & & \\
\hline Ind. risk avoidance & 0.69 & & & & \\
\hline Threats to achievement & 0.71 & & & & 0.38 \\
\hline Family involvement & & & & 0.84 & \\
\hline Physical activity & & & 0.84 & & \\
\hline Social problem solving & 0.66 & & & 0.33 & \\
\hline Academic performance & & & & & 0.84 \\
\hline Peer relations & 0.76 & & 0.33 & & \\
\hline
\end{tabular}

"trouble paying attention at school" is closely related to the core symptoms of ADHD. Therefore, the low correlation with the Risk avoidance domain suggests that in the ADHD population, this item belongs to a different dimension than other items in this domain. Correlation patterns were similar at the end of the double-blind phase for the placebo-controlled studies. However, the weak correlation for item "trouble paying attention at school" was not as distinct as for the baseline assessment in the Risk avoidance domain. Weaker correlations were seen for the changes from baseline analyses.

The assessment of the item-sub-domain correlations yielded a similar pattern for the TA sub-domain, which is part of the Risk avoidance domain, for baseline and endpoint. The items for the PA sub-domain could be separated into two groups based on the correlations with three items that had a much higher correlation with the sub-domain than the other items. Items 44 ("How often did your child play active games or sports?"), 45 ("How often did your child play hard enough to start sweating and breathing hard?"), and 46 ("How often did your child run hard when he/she played or did sports?") had much higher correlations compared with the items 31 ("How often did your child have trouble walking one block?"), 32 ("How often did your child have trouble walking up one flight of stairs?"), and 33 ("How often did your child have trouble running?"). A similar pattern, but with overall weaker correlations, was observed for the changes from baseline.

Correlations between sub-domains and domains and between domains and the total score were similar at baseline and endpoint. The correlations for change from baseline were usually slightly smaller. The RA and the PA sub-domains had lower correlations with their domains than most of the other domains at baseline, at endpoint, and 
also for the change from baseline. The same was found to be true for the Comfort domain regarding the correlation of the domain with the total score. The Achievement domain, the Satisfaction domain, and the Risk avoidance domain seem to be especially important components of the CHIP$\mathrm{CE}$ scale in children and adolescents with ADHD, based on their strong correlation with the total score. The low correlation of the other two domains, Resilience and Comfort, might be caused by the fact that these contain sub-domains that are not affected by ADHD at baseline (PC, RA, and PA). This was not only observed in the present population of patients with ADHD, but also in a cross-sectional sample from the United States on which Riley et al. (2007) based their analysis.

The internal consistency as measured by Cronbach's alpha for all sub-domains was good at baseline and at endpoint, which confirms the findings from an observational study with ADHD patients (Riley et al. 2006b) as well as the results based on a community sample (Riley et al. 2004a). The internal consistency for changes from baseline to endpoint as measured by Cronbach's alpha was moderate, except for AP where it was low. Therefore, the CHIP-CE is generally useful to track changes in QoL over time. The internal consistency of domains and subdomains was robust against single missing items, except for changes in the TA sub-domain and the AP subdomain. Results from those sub-domains should only be used if all items are available. Considerable ceiling effects were only observed for the RA domain, which is not surprising in a sample selected based on a psychiatric and not a physical condition. A similar profile of floor and ceiling effects was seen in an observational study in ADHD patients (Riley et al. 2006b). The RA domain had also most ceiling effect (6.3\%) in a community sample (Riley et al. 2004a). The factor analysis allowing for 12 factors showed that the sub-domains generally load onto different factors; especially the sub-domains that are impaired in ADHD patients can be distinguished. However, this is not the case for the 5-factor solution based on the number of CHIP-CE domains, where the items from sub-domains that do not belong to the same domain often load together on one factor. It is therefore advisable to use the sub-domains rather than the domains of the CHIPCE when evaluating ADHD patients. This is supported by the factor analysis based on the sub-domains and the correlation analysis of the sub-domains, which showed that those sub-domains that belong to the same domain do not necessarily have a high correlation. Riley et al. (2006a) also found a 12-factor solution in a cross-sectional naturalistic ADHD sample. This is an important difference to the results of CHIP-CE domains previously reported in a community sample (Riley et al. 2004a, b; Rajmil et al. 2004). The correlation between the domains over time was stable in our analysis. The same holds true for the sub-domains. A cluster of between-sub-domain correlations was observed for nine sub-domains, which showed correlations of $>0.3$ with three or more subdomains at baseline and/or at endpoint. In contrast, the three sub-domains FI, PA, and AP appeared to be less correlated with the others.

Possible limitations of this evaluation are the different designs of the studies on which this combined analysis was based, including different patient populations with respect to pre-treatment and comorbidities. Therefore, these results may not be directly transferable to epidemiological samples. Furthermore, it is difficult to assess how the proxy evaluation by the parents may have influenced the relationship between QoL and the core symptoms. The influence of the QoL of the parents or the parents' diseases (such as ADHD) could not be assessed because these data were not obtained.

\section{Conclusions}

The strength of this analysis is the large sample of patient data from outside of the United States. This large sample size together with the longitudinal assessment of the questionnaire makes this analysis unique. Previous evaluations of the CHIP-CE used only cross-sectional samples and thus could not assess its performance in measuring changes over time. Our findings suggest that the application of the CHIP-CE provides useful and psychometrical robust insights into the QoL in terms of internal consistency and structure-especially when evaluating the subdomains. Based on this combined analysis, the CHIP-CE can also be recommended to track changes in QoL over time.

Acknowledgments We thank Dr. Birgit Eschweiler for manuscript editing and support.

Conflict of interest The study was sponsored by Eli Lilly and Company. AS and RE are employees and shareholders of Eli Lilly and Company. RE and TW were employees of Eli Lilly and Company during the time he was contributing to this manuscript.

Open Access This article is distributed under the terms of the Creative Commons Attribution Noncommercial License which permits any noncommercial use, distribution, and reproduction in any medium, provided the original author(s) and source are credited.

\section{References}

American Psychiatric Association (2000) Diagnostic and statistical manual of mental disorders, fourth edition, text revision (DSMIV-TR). American Psychiatric Association, Washington, DC 
Barkley RA (2002) Major life activity and health outcomes associated with attention-deficit/hyperactivity disorder. J Clin Psychiatry 63(Suppl 12):10-15

Bastiaens L (2008) Both atomoxetine and stimulants improve quality of life in an ADHD population treated in a community clinic. Psychiatr Q 79:133-137 (published online)

Biederman J, Faraone SV (2005) Attention-deficit hyperactivity disorder. Lancet 366:237-248

Brown RT, Perwien A, Faries DE, Kratochvil CJ, Vaughan BS (2006) Atomoxetine in the management of children with ADHD: effects on quality of life and school functioning. Clin Pediatr (Phila) 45:819-827

Buitelaar JK, Danckaerts M, Gillberg C, Zuddas A, Becker K, Bouvard M, Fagan J, Gadoros J, Harpin V, Hazell P, Johnson M, Lerman-Sagie T, Soutullo CA, Wolanczyk T, Zeiner P, Fouche DS, Krikke-Workel J, Zhang S, Michelson D, for the Atomoxetine International Study Group (2004) A prospective, multicenter, open-label assessment of atomoxetine in non-North American children and adolescents with ADHD. Eur Child Adolesc Psychiatry 13:249-257

Cheng JY, Chen RY, Ko JS, Ng EM (2007) Efficacy and safety of atomoxetine for attention-deficit/hyperactivity disorder in children and adolescents. Meta-analysis and meta-regression analysis. Psychopharmacology (Berl) 194:197-209

Curatolo PP, Mancini F, Dell'Agnello G, the LYCY Study Group (2007) Quality of life of pediatric patients with attention-deficit/ hyperactivity disorder and opposite defiant disorder: an Italian double-blind placebo-controlled study with atomoxetine. Poster presented at the XIII ESCAP congress, 25-29 Aug, Florence, Italy

DeVellis RF (1991) Scale development: theory and applications. Sage, Newbury Park

Dickson RA, Jackiewicz G, Khattak S, Gilchrist W, Szombathy S, Brunner E, Moroz T, Lee B (2007) Change in ADHD symptoms and functional outcomes in Canadian children during 3 months of atomoxetine treatment. Poster presented at the 27th annual conference of the Canadian Academy of Child and Adolescent Psychiatry (CACAP), 11-13 Nov, Montreal, QC

Döpfner M, Steinhausen H-C, Coghill D, Dalsgaard S, Poole L, Ralston SJ, Rothenberger A, ADORE Study Group (2006) Cross-cultural reliability and validity of ADHD assessed by the ADHD rating scale in a pan-European study. Eur Child Adolesc Psychiatry 15(Suppl 1):i46-i55

DuPaul GJ, Ervin RA, Hook CL, McGoey KE (1998a) Peer tutoring for children with attention deficit hyperactivity disorder: effects on classroom behavior and academic performance. J Appl Behav Anal 31:579-592

DuPaul GJ, Power TJ, Anastopoulos AD, Reid R (1998b) ADHD rating scale-IV: checklists, norms, and clinical interpretations. Guilford, New York

Escobar R, Soutullo CA, Hervas A, Gastaminza X, Polavieja P, Gilaberte I (2005) Worse quality of life for children with newly diagnosed attention-deficit/hyperactivity disorder, compared with asthmatic and healthy children. Pediatrics 116:e364-e369

Escobar R, Hervas A, Soutullo C, Mardomingo MJ, Uruñuela A, Gilaberte I (2008) Attention deficit/hyperactivity disorder: burden of the disease according to subtypes in recently diagnosed children. Actas Esp Psiquiatr 36(5):285-294

Escobar R, Montoya A, Polavieja P, Cardo E, Artigas J, Hervas A, Fuentes J (2009) Evaluation of patients' and parents' quality of life in a randomized placebo-controlled atomoxetine study in ADHD. J Child Adolesc Psychopharmacol 19(3):253-263

Escobar R, Schacht A, Wagner T, Wehmeier PM (2010) Quality of life and ADHD core symptoms: a pooled analysis of 5 non-US atomoxetine clinical trials. J Clin Psychopharmacol 30:145-151
Faries DE, Yalcin I, Harder D, Heiligenstein JH (2001) Validation of the ADHD rating scale as a clinician administered and scored instrument. J Atten Disord 5:39-47

Guy W (ed) (1976) ECDEU assessment manual for psychopharmacology. Publication ADM 76-338. US Department of Health, Education and Welfare, Washington, DC, pp 218-222

Hakkart-van Roijen L, Zwirs BWC, Bouwmans C, Tan SS, Schulpen TWJ, Vlasveld L, Buitelaar JK (2007) Societal cost and quality of life of children suffering from attention deficit hyperactivity disorder (ADHD). Eur Child Adolesc Psychiatry 16:316-326

Harpin VA (2005) The effect of ADHD on the life of an individual, their family, and community from preschool to adult life. Arch Dis Child 90(Suppl 1):i2-i7

National Institute of Mental Health (NIMH) (1985) Psychopharmacol Bull 21:839-943

Jensen PS, Hinshaw SP, Swanson JM, Greenhill LL, Conners CK, Arnold LE, Abikoff HB, Elliott G, Hechtman L, Hoza B, March JS, Newcorn JH, Severe JB, Vitiello B, Wells K, Wigal T (2001) Findings from the NIMH multimodal treatment study of ADHD (MTA): implications and applications for primary care providers. J Dev Behav Pediatr 22:60-73

Johnston C, Mash EJ (2001) Families of children with attentiondeficit/hyperactivity disorder: review and recommendations for future research. Clin Child Fam Psychol Rev 4:183-207

Klassen AF, Miller A, Fine S (2004) Health-related quality of life in children and adolescents who have a diagnosis of attentiondeficit/hyperactivity disorder. Pediatrics 114:e541-e547

Landgraf J, Abetz L, Ware J (1996) Child health questionnaire (CHQ): a users manual. Integrated Therapeutics Group, Boston

Leidy NK, Revicki DA, Geneste B (1999) Recommendations for evaluating the validity of quality of life claims for labeling and promotion. Value Health 2:113-127

Matza LS, Rentz AM, Secnik K, Swensen AR, Revicki DA, Michelson D, Spencer T, Newcorn JH, Kratochvil CJ (2004) The link between health-related quality of life and clinical symptoms among children with attention-deficit hyperactivity disorder. J Dev Behav Pediatr 25:166-174

Matza LS, Stoeckl MN, Shorr JM, Johnston JA (2006) Impact of atomoxetine on health-related quality of life and functional status in patients with ADHD. Expert Rev Pharmacoecon Outcomes Res 6:379-390

Michelson D, Faries D, Wernicke J, Kelsey D, Kendrick K, Sallee R, Spencer T, Atomoxetine ADHD Study Group (2001) Atomoxetine in the treatment of children and adolescents with attentiondeficit/hyperactivity disorder: a randomized, placebo-controlled, dose-response study. Pediatrics 108:e83-e91

Montoya A, Hervas A, Cardo E, Artigas J, Mardomingo MJ, Alda JA, Gastaminza X, García-Polavieja MJ, Gilaberte I, Escobar R (2009) Randomized controlled trial of atomoxetine first-line treatment of newly-diagnosed, treatment-naïve cases of attention deficit/ hyperactivity disorder. Curr Med Res Opin 25(11):2745-2754

Nijmeijer JS, Minderaa RB, Buitelaar JK, Mulligan A, Hartman CA, Hoekstra PJ (2008) Attention-deficit/hyperactivity disorder and social dysfunctioning. Clin Psychol Rev 28:692-708

Perwien AR, Faries DE, Kratochvil CJ, Sumner CR, Kelsey DK, Allen AJ (2004) Improvement in health-related quality of life in children with ADHD: an analysis of placebo controlled studies of atomoxetine. J Dev Behav Pediatr 25:445

Perwien AR, Kratochvil CJ, Faries DE, Vaughan BS, Spencer T, Brown RT (2006) Atomoxetine treatment in children and adolescents with attention-deficit hyperactivity disorder: what are the long-term health-related quality-of-life outcomes? J Child Adolesc Psychopharmacol 16:713-724

Polanczyk G, Silva de Lima M, Lessa Horta B, Biederman J, Rohde LA (2007) The worldwide prevalence of ADHD: a systematic 
review and metaregression analysis. Am J Psychiatry 164:942-948

Prasad S, Hapin V, Poole L, Zeitlin H, Jamdar S, Puvanendran on behalf of the SUNBEAM Study Group (2007) A multicentre, randomised, open-label study of atomoxetine compared with standard current therapy in UK children and adolescents with attention-deficit/hyperactivity disorder (ADHD). Curr Med Res Opin 23:379-394

Rajmil L, Berra S, Estrada MD, Serra-Sutton V, Rodríguez M, Borrell C, Riley A, Starfield B (2004) Spanish version of the child health and illness profile-child edition parent report form [CHIP-CE/ PRF]. Gac Sanit 18:305-311

Revicki DA, Osoba D, Fairclough D, Barofsky I, Berzon R, Leidy NK, Rothman M (2000) Recommendations on health-related quality of life research to support labeling and promotional claims in the United States. Qual Life Res 9:887-900

Riley AW, Robertson J, Forrest CB, Green B, Rebok G, Starfield B (2001) Manual for the child health and illness profile-child edition (CHIP-CE). The Johns Hopkins University, Baltimore

Riley AW, Forrest CB, Rebok GW, Starfield B, Green BF, Robertson JA, Friello P (2004a) The child report form of the CHIP-child edition: reliability and validity. Med Care 42:221-231

Riley AW, Forrest CB, Starfield B, Rebok GW, Robertson JA, Green BF (2004b) The parent report form of the CHIP-child edition: reliability and validity. Med Care 42:210-220

Riley AW, Coghill D, Forrest CB, Lorenzo MJ, Ralston SJ, Spiel G, ADORE Study Group (2006a) Validity of the health-related quality of life assessment in the ADORE study: parent report form of the CHIP-child edition. Eur Child Adolesc Psychiatry 15(Suppl 1):i63-i71

Riley AW, Spiel G, Coghill D, Döpfner M, Falissard B, Lorenzo MJ, Preuss U, Ralston SJ, ADORE Study Group (2006b) Factors related to health-related quality of life (HRQoL) among children with ADHD in Europe at entry into treatment. Eur Child Adolesc Psychiatry 15(Suppl 1):i38-i45
Riley AW, Chan KS, Prasad S, Poole L (2007) A global measure of child health-related quality of life: reliability and validity of the child health and illness profile-child edition (CHIP-CE) global score. J Med Econ 10:91-106

Sawyer MG, Whaites L, Rey JM, Hazell PL, Graetz BW, Baghurst P (2002) Health-related quality of life of children and adolescents with mental disorders. J Am Acad Child Adolesc Psychiatry 41:530-537

Schmidt LJ, Garratt AM, Fitzpatrick R (2001) Child/parent-assessed population health outcome measures: a structured review. Child Health Care Dev 28:227-237

Svanborg P, Thernlund G, Gustafsson PA, Hägglöf B, Poole L, Kadesjö B (2009) Efficacy and safety of atomoxetine as add-on to psychoeducation in the treatment of attention-deficit/hyperactivity disorder - a randomized, double-blind placebo controlled study in stimulant-naïve Swedish children and adolescents. Eur Child Adolesc Psychiatry 18:240-249

Wallander JL, Schmitt M, Koot HM (2001) Quality of life measurements in children and adolescents: issues, instruments, and applications. J Clin Psychol 57:571-585

Wehmeier PM, Dittmann RW, Schacht A, Minarzyk A, Lehmann M, Sevecke K, Lehmkuhl G (2007) Effectiveness of atomoxetine in children with attention-deficit/hyperactivity disorder and quality of life as perceived by patients, parents and physicians in an open-label study. J Child Adolesc Psychopharmacol 17:813-830

Wehmeier PM, Schacht A, Lehmann M, Dittmann RW, Silva SG, March JS (2008) Emotional well-being in children and adolescents treated with atomoxetine for attention-deficit/hyperactivity disorder: findings from a patient, parent and physician perspective. Child Adolesc Psychiatry Mental Health 2:10 (published online)

Yang P, Hsu HY, Chiou SS, Chao MC (2007) Health-related quality of life in methylphenidate-treated children with attention-deficit/ hyperactivity disorder: results from a Taiwanese sample. Aust NZ J Psychiatry 41:998-1004 